\title{
Imaging Appearance of Dextranomer/Hyaluronic Acid Copolymer Implant Injections for Treatment of Velopharyngeal Insufficiency
}

W. Brinjikji, S.A. Cofer, and J.I. Lane

\begin{abstract}
BACKGROUND AND PURPOSE: Dextranomer/hyaluronic acid copolymer implants are used in treating velopharyngeal insufficiency. These posterior nasopharyngeal implants can be mistaken for pathologic conditions such as retropharyngeal abscess on imaging. We studied the imaging appearance of dextranomer/hyaluronic acid copolymer implants in patients treated for velopharyngeal insufficiency.
\end{abstract}

MATERIALS AND METHODS: A consecutive series of patients with velopharyngeal insufficiency treated with dextranomer/hyaluronic acid copolymer were included in this study. Data on patient characteristics and volume of dextranomer/hyaluronic acid copolymer injected were obtained. Postoperative imaging characteristics on plain radiography, CT, and MR imaging were assessed. The imaging appearance of postoperative complications was determined.

RESULTS: Sixteen patients were included in this study. Seven patients underwent postoperative plain radiographs, 5 patients underwent $\mathrm{CT}$, and 9 patients underwent MR imaging. Plain radiographs demonstrated soft-tissue swelling in the retropharyngeal space, which resolved at 1 month. On CT, dextranomer/hyaluronic acid copolymer implants appeared as bilateral nasopharyngeal soft-tissue masses isoattenuated to hypoattenuated relative to muscle in $80 \%$ (4/5) of patients. On MR imaging, dextranomer/hyaluronic acid copolymer implants appeared as bilateral nasopharyngeal soft-tissue masses that were isointense to muscle on $\mathrm{Tl}(8 / 9,88.9 \%)$ and hyperintense to muscle on T2 (8/9, 88.9\%) and demonstrated no restricted diffusion (4/4, 100.0\%) or peripheral enhancement $(7 / 7,100.0 \%)$.

CONCLUSIONS: The normal postoperative findings of posterior nasopharyngeal dextranomer/hyaluronic acid copolymer injection on MR imaging is characterized by the presence of bilateral nasopharyngeal soft-tissue masses that are isointense to muscle on $\mathrm{Tl}$ and hyperintense on T2, with no restricted diffusion or peripheral enhancement. Velopharyngeal dextranomer/hyaluronic acid copolymer implants are iso- to hypoattenuated to muscle on CT and are not visible radiographically once associated implantation-related swelling has resolved.

ABBREVIATION: VPI = velopharyngeal insufficiency

$\mathbf{P}$ osterior pharyngeal wall augmentation is a promising technique for the treatment of velopharyngeal insufficiency (VPI). ${ }^{1}$ By augmenting the posterior pharyngeal wall so it extends more anteriorly, an easily reached contact point for the soft palate is created, allowing velopharyngeal closure. Numerous implant materials have been used, including cartilage, fat, paraffin, and calcium hydroxyapatite. ${ }^{1-7}$ Injection of dextranomer/hyaluronic acid has emerged as an effective technique for treating vocal cord dysfunction and laryngeal insufficiency, and augmenting the pos-

Received September 23, 2014; accepted after revision November 17.

From the Departments of Radiology (W.B., J.I.L.) and Otorhinolaryngology (S.A.C.), Mayo Clinic, Rochester, Minnesota.

Please address correspondence to Waleed Brinjikji, MD, Department of Radiology, Mayo Clinic, 200 1st St SW, Rochester, MN 55905; e-mail: brinjikji.waleed@mayo.edu

http://dx.doi.org/10.3174/ajnr.A4246 terior pharyngeal wall in the treatment of VPI..$^{8-12}$ Because many patients receiving these implants will undergo imaging studies unrelated to VPI, characterization of the normal imaging appearance of hyaluronic acid implants in the posterior pharyngeal wall is important to avoid confusion with pathologic processes.

\section{MATERIALS AND METHODS \\ Patient Population}

After institutional review board approval, a retrospective series of patients who received posterior pharyngeal wall augmentation with hyaluronic implants (dextranomer/hyaluronic acid copolymer or hyaluronic acid) between April 1, 2010, and August 31, 2012, and who underwent follow-up imaging was reviewed. For all patients, data on age, sex, underlying disease, and volume of polymer injected were collected. 


\section{Procedural Details}

All surgical procedures were performed by an otorhinolaryngologist. Preoperative nasoendoscopy was used to determine the level of velopharyngeal closure. Patients were treated under general endotracheal anesthesia. A catheter was inserted into each nostril and withdrawn through the oral cavity and clamped to itself to retract the palate. Mirror visualization of the nasopharynx was correlated with the findings of the nasoendoscopy. Following identification of the level of velopharyngeal closure, dextranomer/hyaluronic acid copolymer or hyaluronic acid solution was injected to augment the posterior nasopharyngeal wall. Careful aspiration before the injection was performed to avoid placement

\section{Clinical characteristics of patients treated for velopharyngeal} insufficiency

\begin{tabular}{lc}
\hline \multicolumn{2}{c}{ Characteristics } \\
\hline No. of patients & 15 \\
Mean age (SD) (yr) & $21.3(21.9)$ \\
Median age (yr) (minimum, maximum) & $10(3,68)$ \\
No. (\%) female & $8(53.3)$ \\
Comorbidities (No.) (\%) & \\
Velocardiofacial syndrome & $3(20.0)$ \\
Neurofibromatosis type 1 & $3(20.0)$ \\
Postsurgical complication & $3(20.0)$ \\
Collet-Sicard syndrome & $1(6.7)$ \\
Pierre-Robin sequence & $1(6.7)$ \\
Oculopharyngeal muscular dystrophy & $1(6.7)$ \\
Chiari II & $1(6.7)$ \\
Cleft palate & $1(6.7)$ \\
Sensorineural hearing loss & $1(6.7)$ \\
Injection agent & \\
No. dextranomer/hyaluronic acid copolymer (\%) & $14(93.3)$ \\
No. hyaluronic acid (\%) & $1(6.7)$ \\
Mean (SD) volume of implant injected (mL) & $3.2 \pm 1.2$ \\
\hline
\end{tabular}

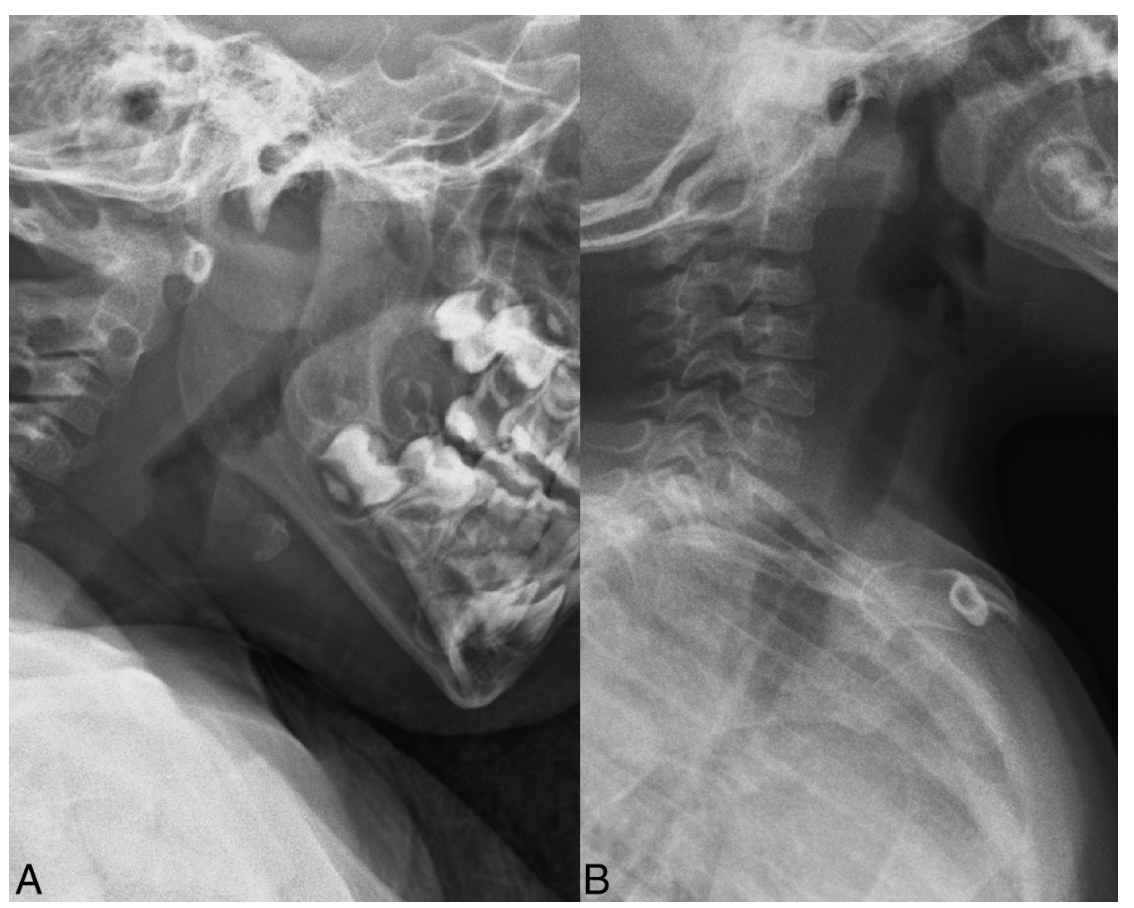

FIG 1. Postoperative radiographs following dextranomer/hyaluronic acid copolymer injection. Images obtained at 2 days $(A)$ and 3 months $(B)$ post-dextranomer/hyaluronic acid copolymer injection demonstrate soft-tissue swelling at 2 days posttreatment $(A)$ and no soft-tissue swelling on the 3-month radiograph $(B)$. within a vessel. Irrigation was then performed, and all hardware was removed from the patient's mouth. Procedural success was generally evaluated with a postoperative endoscopic evaluation and/or a video swallow study.

\section{Imaging Characteristics}

Neck MR imaging was generally performed on $1.5 \mathrm{~T}$ scanners. Fast spin-echo T1 and T2 images were obtained. Imaging parameters for $\mathrm{T} 2$ sequences were the following: $\mathrm{TR}=3000 \mathrm{~ms}$, $\mathrm{TE}=100 \mathrm{~ms}$, section thickness $=4-5 \mathrm{~mm}$, matrix size $=256 \times 256$ pixels. Imaging parameters for $\mathrm{T} 1$ sequences were the following: $\mathrm{TR}=$ $467 \mathrm{~ms}, \mathrm{TE}=10 \mathrm{~ms}$. Postgadolinium imaging was generally performed by using fat-saturated echo-spoiled gradient-echo imaging $(\mathrm{TR}=170 \mathrm{~ms}, \mathrm{TE}=3.2 \mathrm{~ms})$ or fat-saturated spin-echo sequences $(\mathrm{TR}=483 \mathrm{~ms}, \mathrm{TE}=20 \mathrm{~ms})$. Diffusing-weighted imaging was performed by using $\mathrm{TR}=10,050 \mathrm{~ms}$ and $\mathrm{TE}=72 \mathrm{~ms}$. Section thickness was $5 \mathrm{~mm}$ for axial images and $4 \mathrm{~mm}$ for sagittal images. Matrix size was $256 \times 256$ pixels. In general, images were obtained from the orbits to the superior mediastinum. For CT neck imaging, the parameters were the following: $\mathrm{kVP}=120, \mathrm{~mA}=400$, kernel $=\mathrm{H} 41 \mathrm{~s}$, section thickness $=2 \mathrm{~mm}$. Image matrix size was $512 \times 512$ pixels, and FOV was $250 \times 250 \mathrm{~mm}$.

In addition to imaging patients following injection of hyaluronic acid, we imaged a vial of dextranomer/hyaluronic acid copolymer adjacent to a vial of water as a reference standard with both T1- and T2-weighted sequences. T2-weighted image parameters were the following: $\mathrm{TR}=4000 \mathrm{~ms}$, TE $=110 \mathrm{~ms}$, section thickness $=4 \mathrm{~mm}$, matrix size $=256 \times 256$ pixels. Imaging parameters for the $\mathrm{T} 1$ images were the following: $\mathrm{TR}=500 \mathrm{~ms}$, $\mathrm{TE}=11 \mathrm{~ms}$, section thickness $=4 \mathrm{~mm}$, matrix size $=256 \times 256$ pixels.

All imaging was reviewed by a board-certified neuroradiologist with 22 years' experience (J.I.L.). Imaging characteristics studied included postoperative $\mathrm{x}$-ray findings, postoperative CT findings, and postoperative MR imaging findings. For patients receiving postoperative CT studies, data were obtained on the attenuation of the implant relative to surrounding muscle and the appearance of the posterior pharyngeal wall in cases in which contrast was used. For patients undergoing postoperative MR imaging studies, data were obtained on the imaging appearance of the dextranomer/hyaluronic acid copolymer implants relative to surrounding muscle on T1-weighted sequences, T2-weighted sequences, diffusionweighted sequences, and postcontrast T1-weighted sequences. Data on time to imaging were also obtained.

For patients who experienced complications related to dextranomer/hyaluronic acid copolymer injection (ie, retropharyngeal abscess), the appearance 
of these complications on both CT and MR imaging was studied and compared with the normal imaging appearance of dextranomer/hyaluronic acid copolymer implants.

\section{RESULTS}

\section{Patient Population}

Fifteen patients were included in our study. The median age of these patients was 10 years (minimum age $=3$ years, maximum age $=68$ years $)$. Five patients were adults $(33.3 \%)$, and 10 patients (66.6\%) were children. Eight patients were female (53.3\%), and 7 patients were male (46.7\%). Among the patients included in our study, the most common underlying causes of VPI were postsurgical complications after treatment of a malignancy $(3 / 15$, $20.0 \%)$, neurofibromatosis $1(3 / 15,20.0 \%)$, and velocardiofacial syndrome $(3 / 15,20.0 \%)$. The mean volume of hyaluronic acid injected was $3.2 \pm 1.2 \mathrm{~mL}$ (minimum $=1 \mathrm{~mL}$, maximum $=6$ $\mathrm{mL}$ ). Fourteen patients were injected with dextranomer/hyaluronic acid copolymer, and 1 patient was injected with hyaluronic acid. The patient injected with hyaluronic acid alone underwent only CT. Clinical data for the patients included in our study are summarized in the Table.

\section{Imaging Appearance of Hyaluronic Acid Implants}

Plain Radiographs. Seven patients in this study (46.7\%) were studied with plain radiographs at some point in their postoperative period (range $=2$ days to 15 months). Four patients had plain radiographs within 1 month of the procedure. Of these, 3 patients (75.0\%) had prevertebral soft-tissue swelling. Three patients (20\%) had plain radiographs after 1 month, and the plain radiograph findings were normal in all 3 cases. The dextranomer/hyaluronic acid copolymer implants were not specifically visible in any patients on plain radiography. The postoperative radiographic appearance of patients receiving these implants is shown in Fig 1.

CT Appearance. Five patients (33.3\%) underwent CT during the postoperative period $($ minimum $=2$ months, maximum $=9$ months). Four of the patients received dextranomer/hyaluronic acid copolymer injection, and 1 patient received hyaluronic acid implants. On CT, both hyaluronic acid copolymer and hyaluronic acid implants appeared as bilateral nasopharyngeal soft-tissue masses that were isoattenuated to hypoattenuated relative to muscle in $80 \%$ (4/5) of patients. The CT appearance of these implants is demonstrated in Fig 2.

One patient presented with a ring-enhancing retropharyngeal mass with central low attenuation consistent with a large retropharyngeal abscess at 8 months after the procedure. The CT imaging appearance of this retropharyngeal abscess is demonstrated in Fig 3. The abscess was surgically aspirated and grew Grampositive anaerobic bacilli.

MR Imaging Appearance. Nine patients (60.0\%) underwent MR imaging during the postoperative period (minimum $=0$ days, maximum $=18$ months). On MR imaging, dextranomer/hyaluronic acid copolymer implants appeared as bilateral submucosal nasopharyngeal soft-tissue masses that were isointense to muscle on T1 $(8 / 9,88.9 \%)$ and hyperintense to muscle on T2 $(8 / 9$, $88.9 \%)$ and demonstrated no restricted diffusion (4/4, 100.0\%).

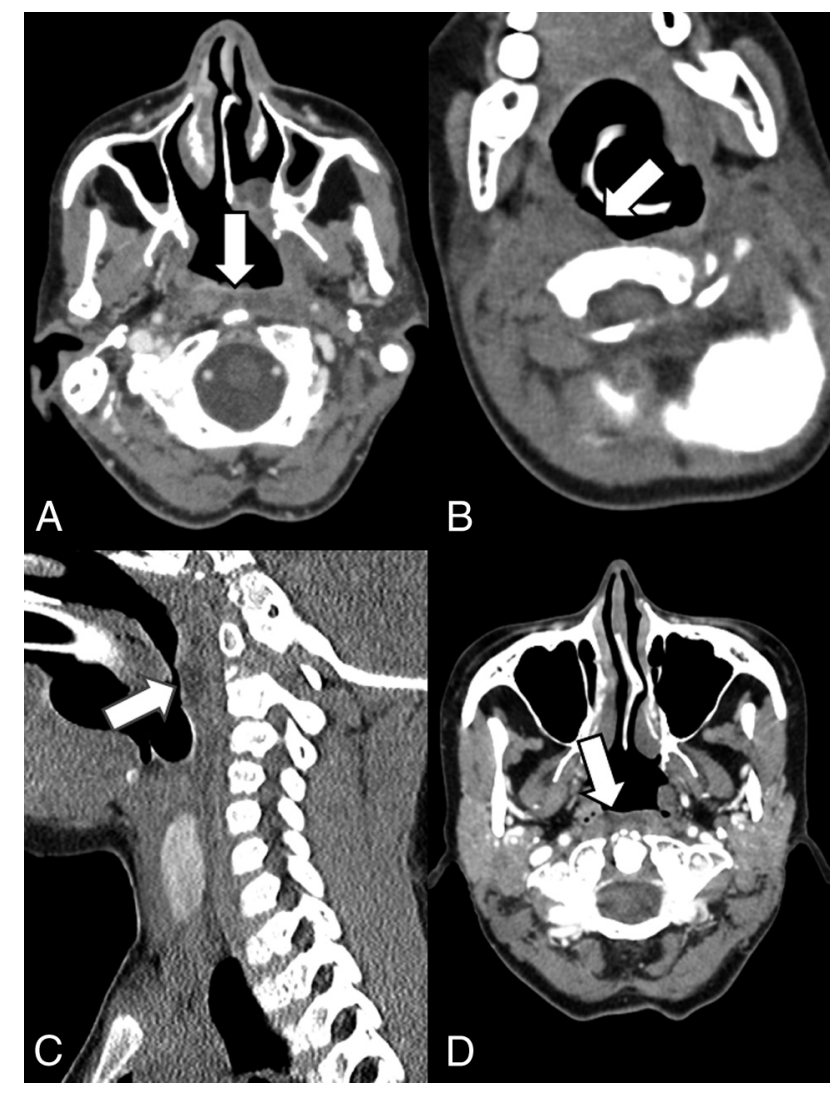

FIG 2. Normal imaging characteristics of dextranomer/hyaluronic acid copolymer injections on CT. A, Contrast-enhanced CT in a 56year-old woman 2 months postinjection of dextranomer/hyaluronic acid copolymer. The white arrow points to a small amount of hypoattenuated fluid in the retropharyngeal space consistent with the injection site. $B$, Noncontrast CT in a 3-year-old boy 3 months status post dextranomer/hyaluronic acid copolymer injection. Hypoattenuation in the right retropharyngeal space (white arrow) indicates the implant. Sagittal images of the patient better demonstrate the hypoattenuation corresponding to the implant (C). D, Contrast-enhanced CT in a 53-year-old woman 9 months post dextranomer/hyaluronic acid copolymer injection demonstrates hypoattenuation in the retropharyngeal space consistent with the implant.

No peripheral enhancement was observed in patients who received gadolinium $(7 / 7,100.0 \%)$. The MR imaging appearance remained stable with time. The MR imaging appearance of these dextranomer/hyaluronic acid copolymer implants is demonstrated in Fig 4. One patient developed a retropharyngeal abscess at the injection site, which was characterized by T2 hyperintensity, mild T1 hyperintensity, restricted diffusion, and peripheral enhancement. This is demonstrated along with the CT appearance in Fig 3.

MR imaging of the ex vivo dextranomer/hyaluronic acid copolymer vial by using T2 imaging parameters demonstrated that the dextranomer/hyaluronic acid copolymer was hyperintense with a signal intensity similar to that of water. Using T1 imaging parameters, the ex vivo dextranomer/hyaluronic acid copolymer was hyperintense with a higher signal intensity than that of water. These findings are demonstrated in Fig 5.

\section{DISCUSSION}

We have demonstrated that on MR imaging, posterior nasopharyngeal hyaluronic acid injection is characterized by the presence of bilateral nasopharyngeal soft-tissue masses that are isointense 
to muscle on $\mathrm{T} 1$ and hyperintense on $\mathrm{T} 2$, with no restricted diffusion or peripheral enhancement. On CT, hyaluronic acid injections are generally iso- to hypoattenuated to adjacent muscle. On plain radiographs, the normal imaging appearance is softtissue fullness within 1 month of the procedure, which normalizes

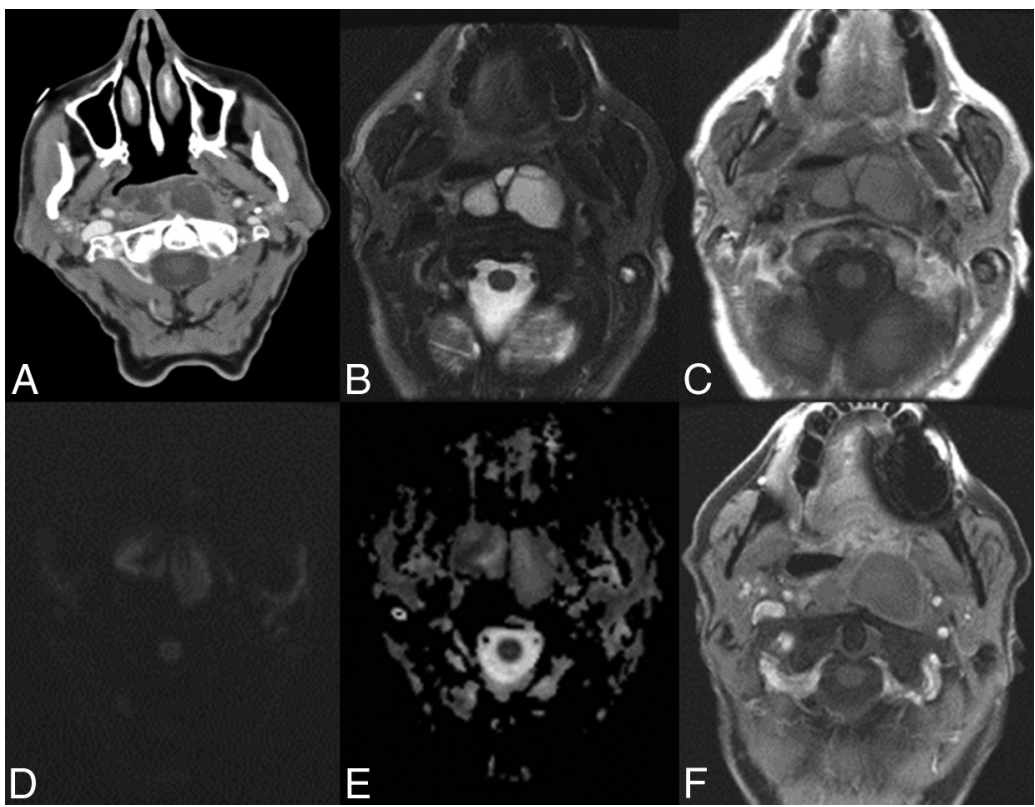

FIG 3. Retropharyngeal abscess 8 months after dextranomer/hyaluronic acid copolymer injection in a 68-year-old man. Retropharyngeal abscess following dextranomer/hyaluronic acid copolymer injection demonstrates mild peripheral enhancement on contrast-enhanced CT $(A)$, internal T2 hyperintensity $(B)$, and mild T1 hyperintensity $(C)$. There are areas of restricted diffusion within the abscess seen on the DWI $(D)$ and ADC $(E)$ images. Peripheral enhancement on postgadolinium echo-spoiled gradient echo is demonstrated as well $(F)$. thereafter. Dextranomer/hyaluronic acid copolymer implants are not radiodense on plain radiography or CT.

These findings are important to recognize to distinguish the normal postoperative imaging appearance of dextranomer/hyaluronic acid copolymer injections from nasopharyngeal pathology. Because VPI is associated with so many diseases in which imaging is involved in the diagnosis and follow-up, it is highly likely that patients with VPI will undergo imaging in which the posterior nasopharynx is included. In our series of patients with VPI who underwent imaging, 3 had undergone surgical treatment for a head and neck/brain malignancy, 3 had neurofibromatosis type 1 , and $3 \mathrm{had}$ velocardiofacial syndrome. Several previous studies have demonstrated a strong association between neurofibromatosis type 1, velocardiofacial syndrome and postradiation, and surgical treatment for head and neck malignancies and VPI. ${ }^{13-17}$

In our series, 1 patient developed a retropharyngeal abscess at the injection site. The imaging appearance of this abscess is clearly distinct from the normal postoperative imaging of hyaluronic acid implants by its increased size, restricted diffusion, and peripheral enhancement. It is important for clinicians and radiologists to be able to distinguish

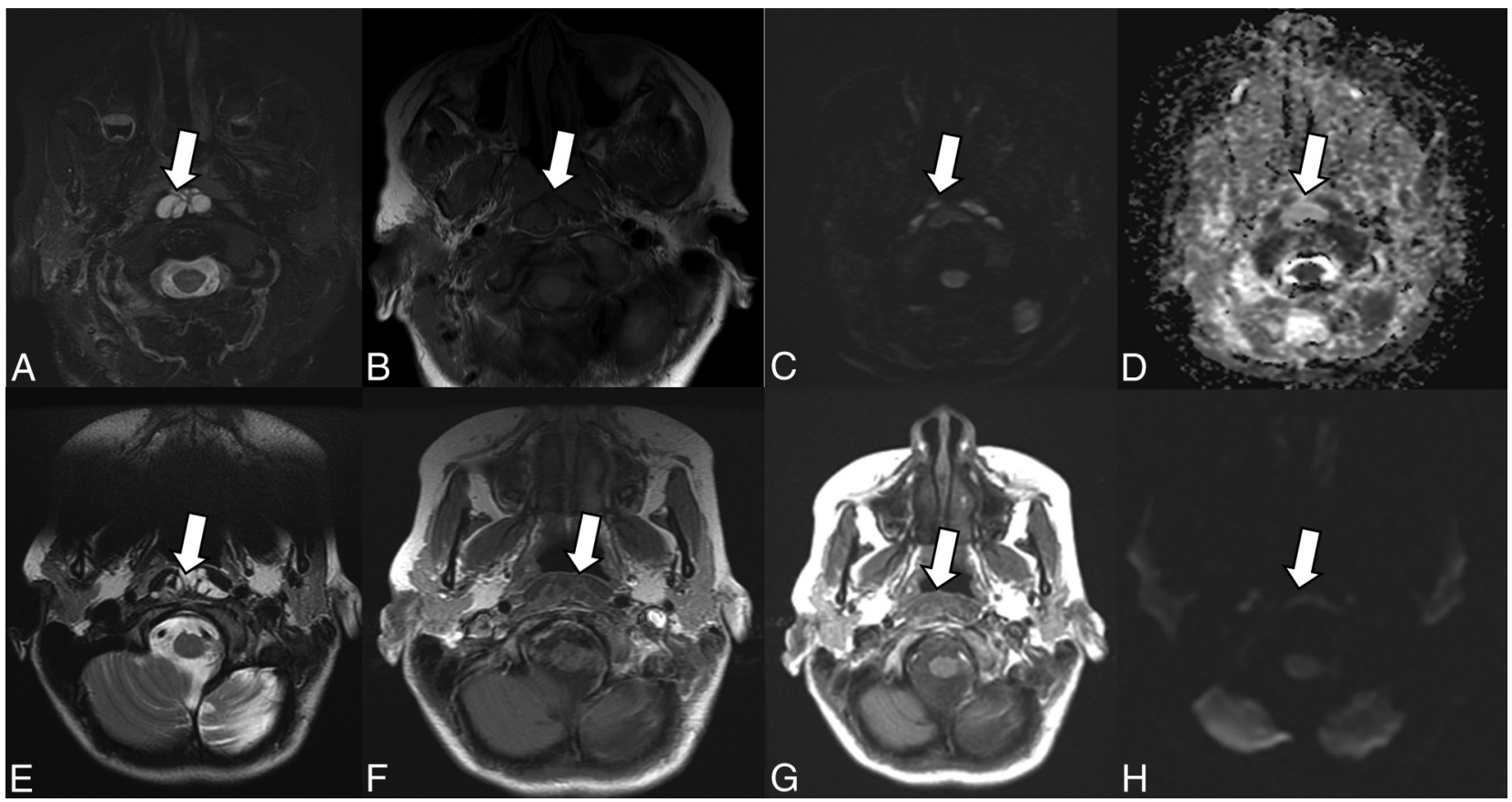

FIG 4. Normal imaging characteristics of dextranomer/hyaluronic acid copolymer injection on MR imaging. MR images in a 71-year-old man status post dextranomer/hyaluronic acid copolymer injection demonstrate a multiloculated T2 hyperintense $(A)$ and T1 isointense lesion $(B)$ on axial images. DWI $(C)$ and $A D C(D)$ images demonstrate no evidence of restricted diffusion. MR images in a 13 -year-old girl 1 month status post injection demonstrate a multiloculated T2 hyperintense $(E)$ and a TT isointense lesion on axial images $(F)$. No evidence of peripheral enhancement is seen on postgadolinium T1-weighted images $(G)$. No evidence of restricted diffusion $(H)$ is seen. 


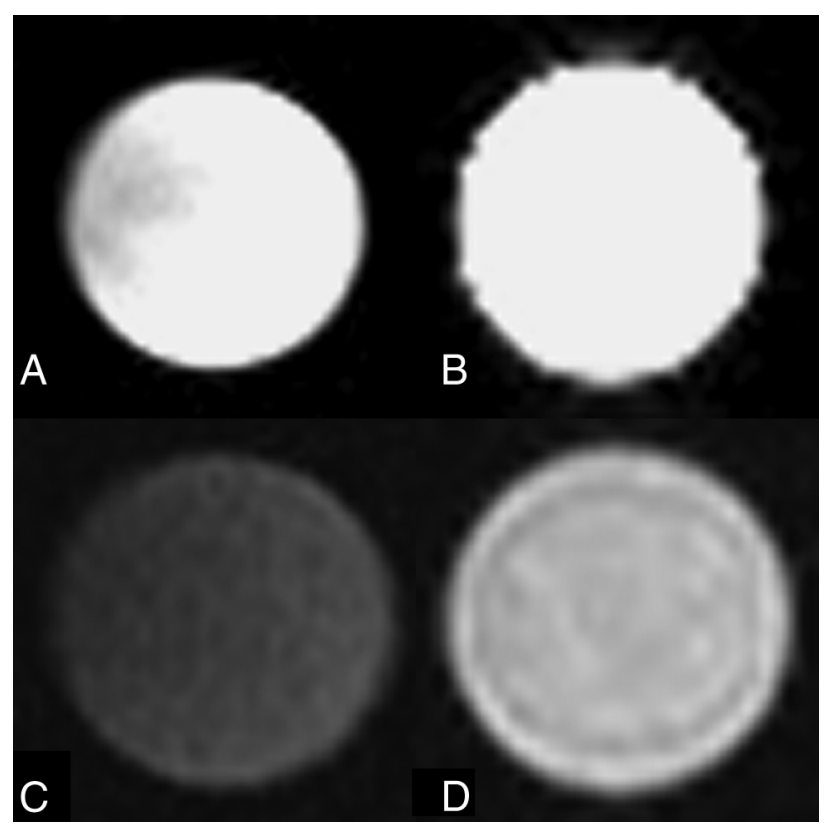

FIG 5. MR imaging characteristics of an ex vivo sample of dextranomer/hyaluronic acid copolymer compared with water. T2 imaging by using a water vial $(A)$ and a vial of dextranomer/hyaluronic acid copolymer solution $(B)$ demonstrates that the dextranomer/hyaluronic acid copolymer solution is hyperintense with a signal intensity similar to that of water. $\mathrm{T1}$ imaging by using a water vial $(C)$ and a vial of dextranomer/hyaluronic acid copolymer $(D)$ demonstrates that the dextranomer/hyaluronic acid copolymer solution is hyperintense to water.

the appearance of a retropharyngeal abscess from the normal appearance of hyaluronic acid to avoid misdiagnosis and unnecessary intervention.

To our knowledge, no studies currently exist on the postoperative imaging findings of patients undergoing posterior pharyngeal wall augmentation with dextranomer/hyaluronic acid copolymer implants. However, the imaging appearance of dextranomer/hyaluronic acid copolymer implants in patients treated for vesicoureteral reflux has been previously described. Similar to our study, hyaluronic acid implants have been shown to have a CT and radiographic attenuation comparable with that of soft tissue. ${ }^{18,19}$ Some studies have demonstrated that these implants can calcify after 24 months. ${ }^{18,19}$ In our study, no evidence of calcification of these implants was seen, but no patients received follow-up radiography or CT after 24 months. On MR imaging, these implants have been shown to be hyperintense on T2-weighted imaging and isointense on T1-weighted imaging. No contrast enhancement is seen. ${ }^{18,20}$ The diffusion characteristics of these implants have not been previously characterized.

\section{Limitations}

There are a number of limitations to our study. Because this was a retrospective study, the use of the various imaging modalities could not be standardized. There is a wide range of follow-up times for postoperative imaging, which limits our ability to determine any temporal changes to the imaging appearance of hyaluronic acid implants. Furthermore, no patients who received dextranomer/hyaluronic acid copolymer implants for
VPI have yet been followed beyond 2 years, the period beyond which calcifications have been reported in the urologic literature.

\section{CONCLUSIONS}

The normal postoperative findings of posterior nasopharyngeal dextranomer/hyaluronic acid copolymer injection are characterized by the presence of bilateral nasopharyngeal soft-tissue masses that are isointense to muscle on T1 and hyperintense on T2, with no restricted diffusion or peripheral enhancement on MR imaging and are iso- to hypoattenuated with adjacent muscle on CT. Familiarity with this appearance is critical in distinguishing the normal postoperative state from nasopharyngeal pathology.

Disclosures: Waleed Brinjikji—UNRELATED: Grants/Grants Pending: Brain Aneurysm Foundation. * *Money paid to the institution.

\section{REFERENCES}

1. Brigger MT, Ashland JE, Hartnick CJ. Injection pharyngoplasty with calcium hydroxylapatite for velopharyngeal insufficiency: patient selection and technique. Arch Otolaryngol Head Neck Surg 2010; 136:666-70

2. Bluestone CD, Musgrave RH, McWilliams BJ, et al. Teflon injection pharyngoplasty. Cleft Palate J 1968;5:19-22

3. Cao Y, Ma T, Wu D, et al. Autologous fat injection combined with palatoplasty and pharyngoplasty for velopharyngeal insufficiency and cleft palate: preliminary experience. Otolaryngol Head Neck Surg 2013;149:284-91

4. Hagerty RF, Hill MJ. Cartilage pharyngoplasty in cleft palate patients. Surg Gynecol Obstet 1961;112:350-56

5. Lando RL. Transplant of cadaveric cartilage into the posterior pharyngeal wall in treatment of cleft palate [article in undetermined language]. Stomatologiia (Mosk) 1950;4:38-39

6. Remacle M, Bertrand B, Eloy P, et al. The use of injectable collagen to correct velopharyngeal insufficiency. Laryngoscope 1990;100: 269-74

7. Sipp JA, Ashland J, Hartnick CJ. Injection pharyngoplasty with calcium hydroxyapatite for treatment of velopalatal insufficiency. Arch Otolaryngol Head Neck Surg 2008;134:268-71

8. Cakli H, Ozudogru E, Cingi E, et al. Near total laryngectomy: the problems influencing functions and their solutions. Eur Arch Otorhinolaryngol 2005;262:99-102

9. Hallén L, Testad P, Sederholm E, et al. DiHA (dextranomers in hyaluronan) injections for treatment of insufficient closure of the vocal folds: early clinical experiences. Laryngoscope 2001;111: 1063-67

10. Hertegård S, Hallén L, Laurent C, et al. Cross-linked hyaluronan used as augmentation substance for treatment of glottal insufficiency: safety aspects and vocal fold function. Laryngoscope 2002;112:2211-19

11. Peterson KL, Fenn J. Treatment of dysphagia and dysphonia following skull base surgery. Otolaryngol Clin North Am 2005;38: 809-17, xi

12. Rickert D. Polymeric implant materials for the reconstruction of tracheal and pharyngeal mucosal defects in head and neck surgery. GMS Curr Top Otorhinolaryngol Head Neck Surg 2009;8: Doc06

13. Jaber JJ, Greenbaum ES, Sappington JM, et al. Postlaryngectomy dysphagia masking as velopharyngeal insufficiency: a simple solution for an anterior neopharyngeal diverticulum. Am J Otolaryngol 2012;33:367-69

14. Oberoi S, Huynh L, Vargervik K. Velopharyngeal, speech and dental characteristics as diagnostic aids in 22q11.2 deletion syndrome. $J$ Calif Dent Assoc 2011;39:327-32 
15. Rosenthal DI, Lewin JS, Eisbruch A. Prevention and treatment of dysphagia and aspiration after chemoradiation for head and neck cancer. J Clin Oncol 2006;24:2636-43

16. Ruda JM, Krakovitz P, Rose AS. A review of the evaluation and management of velopharyngeal insufficiency in children. Otolaryngol Clin North Am 2012;45:653-69, viii

17. Zhang I, Husein M, Dworschak-Stokan A, et al. Neurofibromatosis and velopharyngeal insufficiency: is there an association? J Otolaryngol Head Neck Surg 2012;41:58-64

18. Cerwinka WH, Kaye JD, Scherz HC, et al. Radiologic features of implants after endoscopic treatment of vesicoureteral reflux in children. AJR Am J Roentgenol 2010;195:234-40

19. Cerwinka WH, Qian J, Easley KA, et al. Appearance of dextranomer/ hyaluronic acid copolymer implants on computerized tomography after endoscopic treatment of vesicoureteral reflux in children. J Urol 2009;181:1324-28; discussion 1329

20. Cerwinka WH, Grattan-Smith JD, Scherz HC, et al. Appearance of Deflux implants with magnetic resonance imaging after endoscopic treatment of vesicoureteral reflux in children. J Pediatr Urol 2009;5:114-18 